\title{
Effects of micro-injection moulding process parameters on accuracy and precision of thermoplastic elastomer micro rings
}

\author{
Baruffi, Federico; Calaon, Matteo; Tosello, Guido
}

Published in:

Precision Engineering

Link to article, DOI:

10.1016/j.precisioneng.2017.09.006

Publication date:

2018

Document Version

Peer reviewed version

Link back to DTU Orbit

Citation (APA):

Baruffi, F., Calaon, M., \& Tosello, G. (2018). Effects of micro-injection moulding process parameters on accuracy and precision of thermoplastic elastomer micro rings. Precision Engineering, 51, 353-361.

https://doi.org/10.1016/j.precisioneng.2017.09.006

\section{General rights}

Copyright and moral rights for the publications made accessible in the public portal are retained by the authors and/or other copyright owners and it is a condition of accessing publications that users recognise and abide by the legal requirements associated with these rights.

- Users may download and print one copy of any publication from the public portal for the purpose of private study or research.

- You may not further distribute the material or use it for any profit-making activity or commercial gain

- You may freely distribute the URL identifying the publication in the public portal

If you believe that this document breaches copyright please contact us providing details, and we will remove access to the work immediately and investigate your claim. 


\section{Accepted Manuscript}

Title: Effects of micro-injection moulding process parameters on accuracy and precision of thermoplastic elastomer micro rings

Authors: Federico Baruffi, Matteo Calaon, Guido Tosello

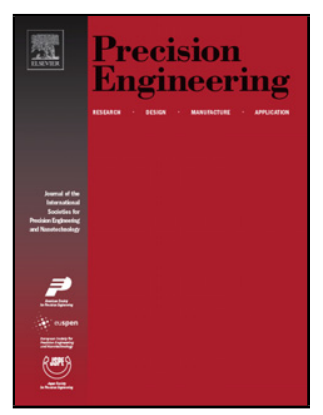

PII:

S0141-6359(17)30220-9

DOI: http://dx.doi.org/10.1016/j.precisioneng.2017.09.006

Reference: PRE 6656

To appear in: Precision Engineering

Received date: 19-4-2017

Revised date: 8-9-2017

Accepted date: 10-9-2017

Please cite this article as: Baruffi Federico, Calaon Matteo, Tosello Guido.Effects of micro-injection moulding process parameters on accuracy and precision of thermoplastic elastomer micro rings.Precision Engineering http://dx.doi.org/10.1016/j.precisioneng.2017.09.006

This is a PDF file of an unedited manuscript that has been accepted for publication. As a service to our customers we are providing this early version of the manuscript. The manuscript will undergo copyediting, typesetting, and review of the resulting proof before it is published in its final form. Please note that during the production process errors may be discovered which could affect the content, and all legal disclaimers that apply to the journal pertain. 


\section{Effects of micro-injection moulding process parameters on accuracy and precision of thermoplastic elastomer micro rings}

\section{Federico Baruffi*, M atteo Calaon, G uido Tosello}

Department of Mechanical Engineering, Technical University of Denmark, Building 427A, DK2800 Kongens Lyngby, Denmark

*Corresponding author. Tel.: +45 452548 22; Fax: +45 45251961

E-mail address: febaru@mek.dtu.dk (Federico Baruffi)

Keywords: Micro-injection moulding, Thermoplastic elastomer, Process analysis, Design of experiments, Optical metrology

Highlights

- An experimental study on the micro-injection moulding process of TPE micro rings.

- Process window identified using SEM inspections and weld line depth measurements.

- Measurements performed using a focus variation microscope and their uncertainty evaluated.

- The micro ring geometry is sensitive to micro-injection moulding process parameters.

- The process has an opposite influence on the rings outer and inner diameter.

\section{ABSTRACT}

Micro-injection moulding $(\mu \mathrm{IM})$ represents the only technology currently capable of enabling the mass production of polymer micro-components. Although this process is mainly utilized to process rigid thermoplastics, the development of new fields of application asks for the extension of the technology potential to novel types of polymeric materials such as soft thermoplastic elastomers (TPEs). In this work, the authors studied the $\mu$ IM technology of TPE micro suspension rings for sensor applications. A $n$ initial benchmark study, based on microscopy inspections and weld line depth measurements, allowed identifying suitable process parameters settings. Then, the effects of the process parameters on the dimensional variation of the outer and inner diameter of the produced micro rings were quantified. A focus 
variation microscope was employed for the measurements of both parts and mould cavities. The results of this study showed that the outer ring diameter was mostly affected by mould temperature and holding pressure, while the inner one depended mainly on mould and melt temperature. It was also found that the investigated process parameters had an opposite effect on the outer and inner diameter variations, posing great challenges in the achievement of the part geometry specified in the design.

\section{Introduction}

Over the last decade, the need of miniaturized, complex-shaped components has drastically increased in several fields such as medicine, biotechnology, automotive, avionics, communication, etc. [1]. In order to meet this fast growing request of both precision and productivity, the manufacturing community reacted by either designing brand new micromanufacturing processes or by developing well established ones and adapting them to the new challenging demands [2].

Within this scenario, micro-injection moulding $(\mu \mathrm{IM})$ represents the miniaturized counterpart of the conventional injection moulding technology. The peculiarity of this process lies in the fact that it successfully combines the cost-effective production of complex and net-shaped plastic parts with the capability of accurately and precisely manufacturing micro components [3]. In order for a product to be considered in the $\mu \mathrm{IM}$ domain, it has to belong to one of the following categories [4], [5]:

- Parts with outer dimensions in the millimetre range or larger, but locally featuring structures in the micrometre range. This class is typical of microfluidic devices.

- Parts with larger outer dimensions but dimensional tolerances in the micrometre range.

- Small parts with outer dimensions in the micrometre scale and mass in the milligram order.

Being the miniaturized adaption of conventional injection moulding, $\mu \mathrm{IM}$ presents the same overall process cycle: the plastic granules are melted, metered and then injected into the mould cavity in the form of a viscoelastic polymer flow. A fter packing and cooling, the moulded 
product is ejected. However, even though the physics behind the two technologies is the same, new challenges and fundamental differences arise when downscaling the process [6]. In fact, dedicated micro machines, micro tooling processes, different modelling approaches and new measuring solutions are all needed to carry out a repeatable and controllable injection moulding process in the microscale [7-9]. In order to face all these challenges, extensiveresearch has been carried out in the last decade. Nowadays, the $\mu \mathrm{IM}$ process is fairly developed in the field of rigid thermoplastics. These materials, being low cost, relatively easy to process and stiff, cover a preponderant part of the polymer materials processed by $\mu \mathrm{IM}$. In fact, the current main application of $\mu \mathrm{IM}$ is represented by the microfluidic devices industry, which relies on the manufacturing of rigid and micro/ nano structured 2.5D parts [10]. Table 1 reports examples of the most commonly thermoplastic polymers used in $\mu \mathrm{IM}$ and their applications.

Table 1 Rigid thermoplastics used in $\mu$ IM components.

\begin{tabular}{lll}
\hline Materials & Micro-applications & Reference \\
\hline Polyoxymethylene (POM) & Micro filter, Dog-bone tensile sample & {$[11],[12]$} \\
Polycarbonate (PC) & Ultra-high aspect ratio nano-pillars, Optical part & {$[13],[14]$} \\
Liquid Crystal Polymer (LCP) & Toggle for hearing aids & {$[15],[16]$} \\
Poly(methyl methacrylate) (PM MA) & Nano-structured part, Microfluidic platform & {$[17],[18]$} \\
Polypropylene (PP) & Micro-structured part, Microfluidic distributor & {$[19],[20]$} \\
Acrylonitrile Butadiene Styrene (ABS) & Micro pillars, Microfluidic part & {$[21],[22]$} \\
Polystyrene (PS) & Bio-MEMS component, Micro-structured part & {$[23],[24]$} \\
Cyclic Olefin Copolymer (COC) & Micro-featured part, Microfluidic device & [25], [26] \\
\hline
\end{tabular}

The research on $\mu \mathrm{IM}$ applied to other classes of polymeric materials is very limited. New research has to be carried out to extend the technology potential to new materials in order to broaden its fields of application. With this aim, this present paper focuses on thermoplastic elastomers (TPEs).

Thermoplastic elastomers are polymeric materials that combine the melt processability typical of thermoplastics and the elastomeric behaviour of vulcanized rubbers [27]. The fundamental difference between rigid thermoplastics and TPEs regards their mechanical properties: the first are rigid and stiff, while the second are soft and flexible. Therefore, TPEs exhibit the distinctive characteristics of thermoset rubbers and are, at the same time, easy to process as thermoplastic polymers. The explanation of the ambivalent behaviour of thermoplastic elastomers lies in their 
structure. M ost TPEs are phase-separated systems: one phase is hard and crystalline at room temperature, while the other is an elastomer [27]. The hard phase confers the strength and acts as physical cross-link, whereas the elastomeric one interconnects the rigid phases providing flexibility and elasticity to the system. The transition temperatures of TPEs, and thus their process window, are determined by the characteristics of both the phases. Below the glass transition of the elastomeric phase, the TPE is brittle and stiff. A bove this temperature, the material is soft and elastic, similarly to rubber. Finally, when the temperature is higher than the melting temperature or glass transition temperature of the hard phase, the TPE turns into a viscous fluid and becomes processable by means of injection moulding. TPEs are usually preferred to thermoset rubbers because of their simpler manufacturing process and shorter fabrication times [27]. The possible re-moulding also represents an important advantage. Finally, the exceptional repeatability of the injection moulding process allows manufacturing TPE components with tighter tolerances compared to conventional thermosets rubbers. Thus, thermoplastic elastomers represent the best solution for manufacturing precision and micro parts featuring softness and flexibility.

Although the injection moulding process of TPEs is well established and widespread for macro scaled components [28], very few studies report about their use in combination with $\mu \mathrm{IM}$. A labran et al. [29] studied the effects of process conditions and tooling on the replication of nano-scale features (patterns size ranging from $100 \mathrm{~nm}$ to $1500 \mathrm{~nm}$ ) using two different thermoplastic polyurethanes and varying only the mould temperature. Attia et al. [30] proposed and validated the micro-overmoulding process of TPE for the manufacture of a 3D microfluidic system. The rigid substrate was made of PMMA while the TPE was a styreneethylene-butylene-styrene (SEBS) copolymer. The assembled device was tested against leakage, but no study regarding the process parameters effect on the product dimensional accuracy was performed.

The present paper studies the $\mu$ IM technology of TPE miniaturized suspension rings employed in sensor applications. An initial benchmark study based on scanning electron microscopy and weld line depth measurements allowed identifying a suitable process window. Then, a 
comprehensive experimental study based on design of experiments (DOE) was carried out in order to evaluate the effects of the moulding process on the part functional geometries. With the aim of evaluating the actual replication capability of the process, the mould cavities were also measured and used as reference for the investigation.

\section{Materials and methods}

\subsection{Case study}

The micro component under investigation was a TPE micro suspension ring utilized as a component of a micro sensor. Since this application demands both high dimensional accuracy and dampening properties, $\mu \mathrm{IM}$ of TPE represents the only solution allowing meeting the functional requirements. Fig. 1 shows the shape and main dimensional features of the investigated suspension micro ring.

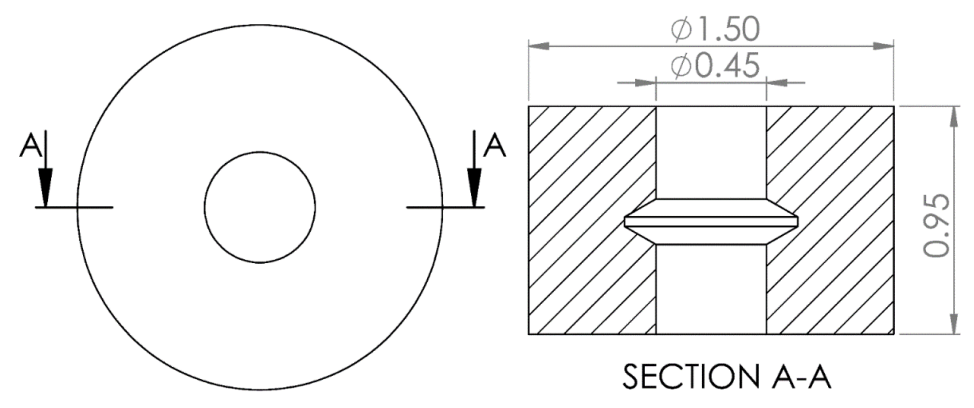

Fig. 1. Geometry and nominal dimensions in mm of the micro suspension ring.

The internal geometry of the ring presents a conical structure, making the component three dimensional. Being the part mass equal to $2.2 \mathrm{mg}$ and the dimensional tolerances $\pm 10 \mu \mathrm{m}$ on both internal and external diameters, the component falls in the category of micro products according to the aforementioned definitions.

The present work focuses on the outer dimeter (OD) and internal diameter (ID) of the rings, since they represent the most significant geometries with respect to the part functionality.

\section{$2.2 \mathrm{M}$ ould design}

A three-plate mould with replaceable insert was developed and used in the experiments. The main advantage of this type of mould is that the separation of the part from the feeding system 
is achieved automatically by means of the movement of the middle plate. The use of such a strategy is relatively common in conventional injection moulding, but few examples of threeplate moulds utilized for $\mu \mathrm{IM}$ purposes exist [30-32]. Both the mould plates and the insert were made from tool steel. Four cavities were machined on the insert and the internal geometry of

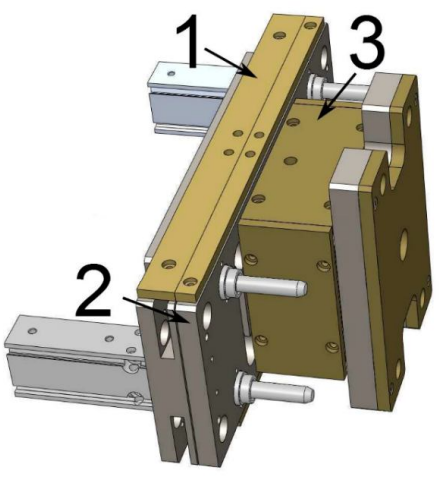

(a)

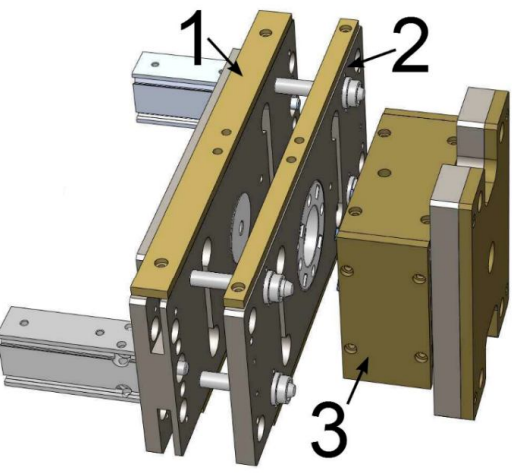

(b)

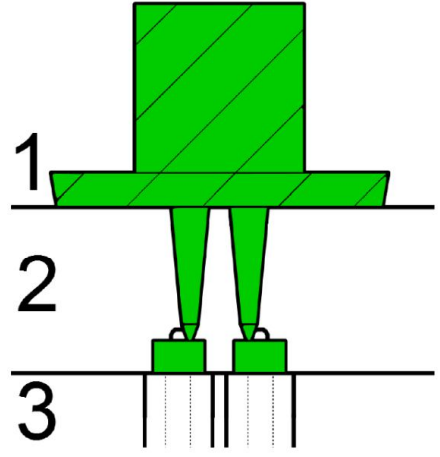

(c)

Fig. 2. TPE mould design. (a) Closed mould, (b) Open mould, (c) Mould cross section. The three plates (1, 2 and 3 ) and theTPE moulded material (in green) are also indicated.

the micro rings was created by means of micro pins protruding from the fixed ejection plate. Both the cavities and the micro pins were machined using micro-electro-discharge-machining $(\mu E D M)$. Taking into account both the nominal shrinkage of theTPE material and the target part dimensions, the four cavities were designed with diameter $1.550 \mathrm{~mm}$ while the pins with diameter $0.480 \mathrm{~mm}$. The parts feed system consisted in a cylindrical sprue connected to the cavities through four runners and pin gates. Fig. 2(a) and 2(b) illustrates the design of the threeplate mould. Fig. 2(c) shows how the feeding system was located in the mould frame

After the end of each moulding cycle, the four micro rings were ejected by means of ejector tubes around the pin, thus ensuring a full automatic procedure. It is worth noting that such an ejection system relies on the softness and elasticity of TPE. In fact, the undercut introduced by the internal rings geometry (see Fig. 1) would have made the ejection impossible if a rigid thermoplastic material was used. Fig. 3(a) and 3(b) show the internal details of the four micro cavities on the ejection and injection sides respectively. 


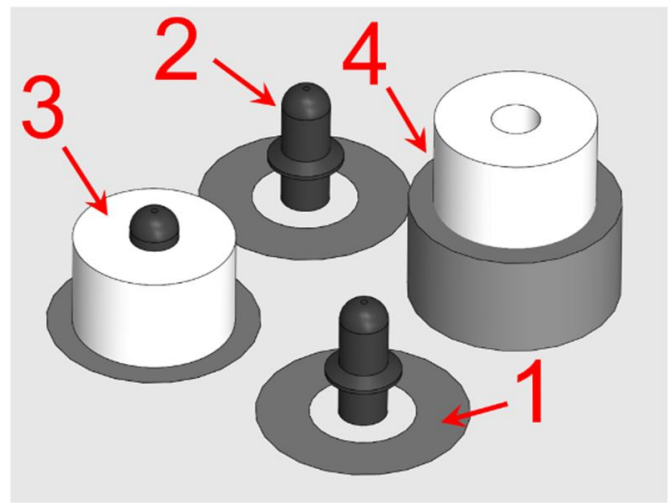

(a)

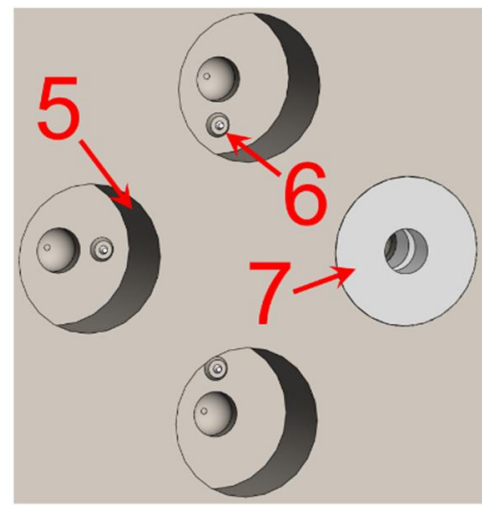

(b)

Fig. 3. (a) Close-up of the ejection side of the mould. 1: ejector tube in neutral position. 2: Pin forming the internal ring geometry 3: Moulded suspension ring before ejection 4: Ejected suspension ring with ejector tube in forward position (b) Close up of the injection side of the mould. 5: Cavity wall creating the outer dimensions of the suspension ring. 6: Asymmetrical gate location 7: Suspension ring inside the cavity.

\subsection{Experimental details}

Injection moulding experiments were performed using a state-of-the-art Wittmann-Battenfeld MicroPower $15 \mu \mathrm{IM}$ machine (maximum clamping force: $150 \mathrm{kN}$, maximum injection velocity: $750 \mathrm{~mm} / \mathrm{s}$ ). The machine presents a $14 \mathrm{~mm}$ plasticisation screw and a separated $5 \mathrm{~mm}$ injection plunger. The thermoplastic elastomer used for the moulding was a styrene-ethylene-butylenestyrene (SEBS). This material is suitable for the application due to its high flowability and enhanced dampening properties. Table 2 reports the main properties of the material.

Table 2 Main properties of the TPE material.

\begin{tabular}{lccc}
\hline Property & Units & Value & Test method \\
\hline Density & $\mathrm{g} / \mathrm{cm}^{3}$ & 0.90 & ISO 2781 \\
Melting Flow Index, MFI & $\mathrm{g} / 10 \mathrm{~min}$ & 68.0 & ISO 1133 \\
Melting point & ${ }^{\circ} \mathrm{C}$ & 153 & DSC \\
\hline
\end{tabular}

The particularly low viscosity of the TPE material, indicated by the large MFI value, makes it suitable for $\mu \mathrm{IM}$, since a very low flow resistance is usually needed to completely fill the micro cavities. If, on one hand, this characteristic has a positive effect on the process feasibility, on the other, the very low viscosity facilitates the appearance of product defects such as flashes. A nother consequence of the low viscosity is that the mould temperature utilized when 
moulding TPE is typically set to a level lower than the ones usually employed with rigid thermoplastics.

In order to identify a suitable processing window for the $\mu \mathrm{IM}$ process of the micro suspension ring, a preliminary benchmark study was performed. Three different process setting combinations were tested and their resulting production batches evaluated. The first combination was called "Data sheet" since it corresponded to the moulding settings recommended by the material manufacturer. The second, called "High", employed parameters higher than the recommended ones to observe possible improvements in filling and replication quality, as often reported in literature [3]. Finally, the process settings of the third batch, called "Improved", were found as part of an operational optimization that aimed at achieving better cavity filling and smaller defects on the produced micro rings. This optimization was based on manual inspection under an optical microscope right after moulding. Table 3 lists the process parameters utilized for the benchmark study.

Table 3 Process parameters for the three batches investigated in the preliminary benchmark study.

\begin{tabular}{lccc}
\hline Process parameter & Data sheet & High & Improved \\
\hline Melt temperature $\left[{ }^{\circ} \mathrm{C}\right]$ & 185 & 200 & 200 \\
Mould temperature $\left[{ }^{\circ} \mathrm{C}\right]$ & 40 & 60 & 40 \\
Clamping force $[\mathrm{kN}]$ & 100 & 100 & 30 \\
Injection speed $[\mathrm{mm} / \mathrm{s}]$ & 120 & 200 & 85 \\
Holding pressure $[\mathrm{bar}]$ & 300 & 750 & 275 \\
\hline
\end{tabular}

In order to evaluate the micro suspension rings produced using the three different process settings, a scanning electron microscope (SEM) was used to perform a qualitative evaluation. M oreover, the depth of the weld line on the injection side, caused by the asymmetric gating of the ring (see Fig. 3), was also taken into account for identifying the best process settings. Weld lines are particularly critical since they represent both a visual defect and a zone of reduced strength for the moulded part [33]. For this analysis, ten produced rings per batch were randomly selected and successively inspected. 
The outcome of theinitial benchmark study was used as a starting point for the successive experimental phase, in which a design of experiment (DOE) approach was employed for evaluating the effects of the process on the rings OD and ID. Four parameters were varied: melt temperature, mould temperature, injection speed and holding pressure. A general full factorial design was carried out. In particular, melt and mould temperature were varied on two levels, while three levels of injection speed and holding pressure were tested (see Table 4). This particular design was selected since preliminary $\mu \mathrm{l} \mathrm{M}$ tests showed that melt and mould temperature did not have any relevant non-linear effects on the outputs. Considering also that a Iong time was needed to reach thermal equilibrium of both polymer melt and mould steel and therefore to change level of these parameters, it was decided to vary them on two levels only in order to reduce the experimental effort.

Table 4 DOE process settings.

\begin{tabular}{lc}
\hline Process parameters & Levels \\
\hline Melt temperature, $T_{\text {met }}\left[{ }^{\circ} \mathrm{C}\right]$ & 210,225 \\
Mould temperature, $T_{\text {mould }}\left[{ }^{\circ} \mathrm{C}\right]$ & 30,40 \\
Injection speed, Vinj $[\mathrm{mm} / \mathrm{s}]$ & $50,70,90$ \\
Holding pressure, phold $[\mathrm{bar}]$ & $300,500,700$ \\
\hline
\end{tabular}

Five replications were produced for each one of the 36 process parameter combinations. The parts moulded during the first ten cycles were discarded in order to evaluate only the effects of a stable moulding process. Considering the presence of four cavities in the mould insert, a total number of 720 micro suspension rings were produced and measured. By doing this, the effect of the different cavities on the measured outputs could be quantitatively investigated.

2.4 M easurement strategy and uncertainty evaluation 
The depth of the weld line was measured using a 3D state-of-the-art focus variation microscope (A licona InfiniteFocus) with $0.25 \mu \mathrm{m}$ vertical resolution and a $1.75 \mu \mathrm{m}$ lateral resolution. The entire weld line on the injection side was acquired. The depth was evaluated in five different positions (see Fig. 4) using cross sectional profiles.

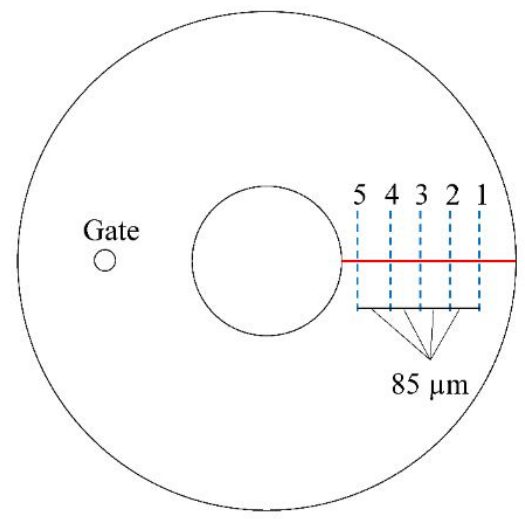

(a)

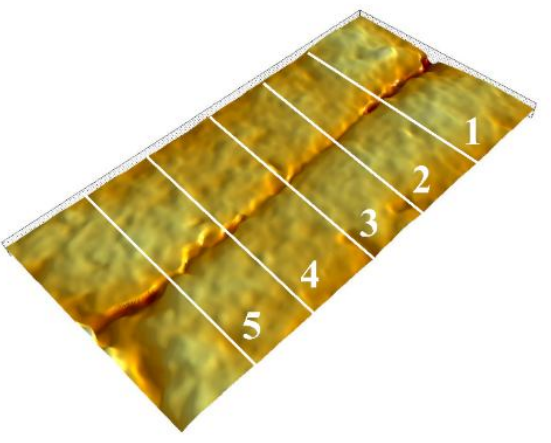

(b)

Fig. 4. (a) Scheme of the five measuring positions al ong the weld line (in red). (b) Three-dimensional scan of the weld line.

The same focus variation microscope was used for measuring the outer and inner diameters of the TPE micro rings. The measurements of the outer and inner diameters were extrapolated from each 3D optical reconstruction by fitting the points of the two circles (see Fig. 5). In particular, the ring face corresponding to the injection side was captured. For each part, three consecutive acquisitions were carried out and their average value was then taken as output of the measuring operation. A long with the produced micro rings, also the four mould cavities were measured in order to assess the replication level of the $\mu$ IM process. In fact, especially when dealing with the extremely demanding precision and accuracy of miniaturized products, a complete knowledge of the tool geometry is fundamental in order to characterize the effect of the process on the dimensional quality. For this purpose, an optical coordinate measuring machine with $0.5 \mu \mathrm{m}$ lateral resolution was employed to measure the cavity diameters (corresponding to the ring OD) and the pins diameters (corresponding to the ring ID). In order to verify the quality of the measurements, an uncertainty assessment was carried out. The measurement uncertainty $\mathrm{U}$ is a parameter that characterizes the dispersion of the values that could be reasonably be attributed to the measurand [34]. The evaluation of such a factor is of 
paramount importance. In fact, when dealing with a design of experiments study, a large uncertainty interval can partially or even totally hide the effects of the experimental factors [35]. In this study, the uncertainty of the measurements of both TPE parts and mould was calculated following ISO 15530-3 [36]. Such a procedure is based on the substitution method: by measuring a calibrated artefact sharing similar characteristics with the actual measurand, the systematic error of the measuring instrument is quantified. For the current investigation, a calibrated circle of diameter $1 \mathrm{~mm}$ was utilized. In particular, five uncertainty sources were considered: $u_{\text {cal }}$, related to the calibration certificate of the utilized artefact; $u_{p}$, the uncertainty associated with the measurement procedure calculated as standard deviation of ten repeated measurements on the calibrated circle; $u_{b}$, related to the systematic error of the measurement process; $u_{\text {res, }}$ introduced by the lateral resolution of the instrument and calculated considering a rectangular resolution interval and $u_{w}$, related to the material and manufacturing variations of the actual measurand. For mould measurements, $u_{w}$ was calculated as standard deviation of ten repeated measurements of the mould OD and ID. For the moulded parts, it was calculated as standard error of the measurements of the parts related to each injection moulding process parameters combination. Therefore, it also includes the uncertainty contribution due to the $\mu \mathrm{lM}$ process. The expanded uncertainty $U$ was then obtained using the law of propagation of uncertainty [34]:

$$
U=k \cdot\left(u_{c a l}{ }^{2}+u_{p}^{2}+u_{b}^{2}+u_{r e s}^{2}+u_{w}^{2}\right)^{1 / 2}
$$

and considering a coverage factor $k$ of 2 in order to achieve a $95 \%$ of confidence level.

Table 5 reports the uncertainty budget for both mould cavity and moulded TPE measurements.

Table 5 Mean values of uncertainty contributions and expanded uncertainty for OD and ID measurements for both mould and moulded part.

\begin{tabular}{lcccc}
\hline Uncertainty contributions & \multicolumn{2}{c}{ Mould cavities } & \multicolumn{2}{c}{ Moulded parts } \\
\cline { 2 - 5 } & OD $[\mu \mathrm{m}]$ & ID $[\mu \mathrm{m}]$ & OD $[\mu \mathrm{m}]$ & ID $[\mu \mathrm{m}]$ \\
\hline$u_{\text {cal }}$ & 0.5 & 0.5 & 0.5 & 0.5 \\
$u_{p}$ & 0.09 & 0.09 & 0.09 & 0.09 \\
$u_{b}$ & $5 \cdot 10^{-5}$ & $5 \cdot 10^{-5}$ & $5 \cdot 10^{-5}$ & $5 \cdot 10^{-5}$
\end{tabular}




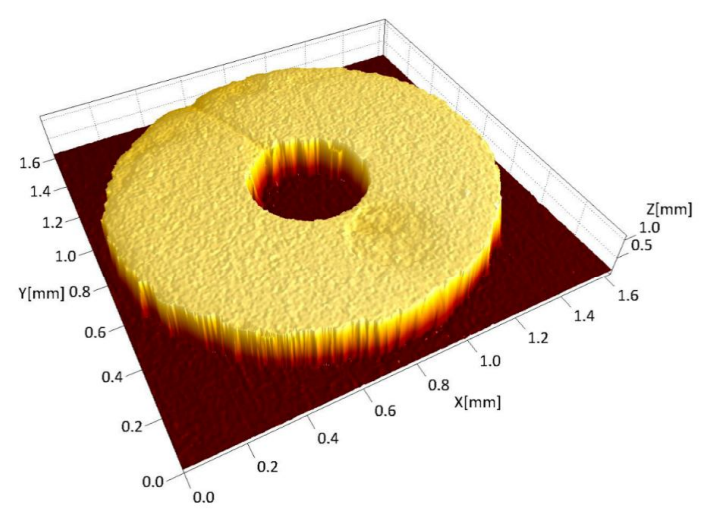

(a)

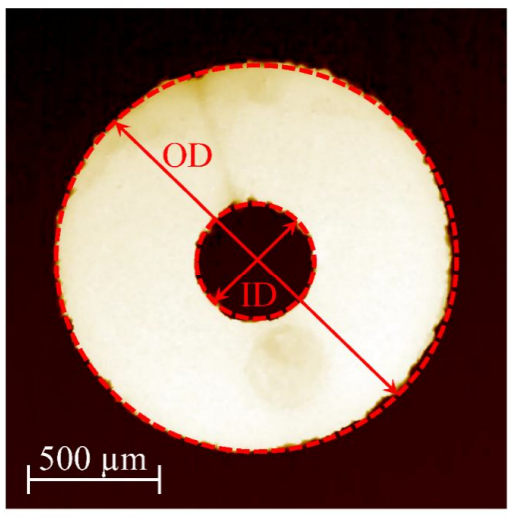

(b)

Fig. 5. (a) Three-dimensional scan of a suspension ring. (b) Interpolated inner and outer circle.

\section{Results}

\subsection{Benchmark study results}

In order to evaluate the quality of the main suspension ring features, three details were captured, namely the injection side view, the internal geometry and the hole at the ejection side. With the aim of observing the internal geometry, the parts were cut in half. It must be noted that the imperfect straightness of the internal side walls of the central hole was due to the imperfect alignment of the manual cutting process, and not to the actual internal shape of the micro rings.

Fig. 6 shows the SEM scans of rings produced with thethree different process settings combination (see Table 3).

When considering the "Data sheet" setting, it may be observed from the injection side view that the residual gate mark, left by the automatic detachment of the feeding system from the part, was relatively small. Moreover, it did not protrude from the surface, which is a convenient feature for precision micro assembly operations when flat surfaces are required. A small weld line was present, caused by the not symmetric gating of the part. From the cross-section, it can 
be seen that the internal geometry was not well defined. In particular, the internal corners looked morerounded than in the design (see Fig. 1). This difference was most probably due to the tooling process capability, which could not create perfectly sharp angles on the pin geometry. The ejection side hole presented a relevant defect caused by the presence of a weld line. The entrapped air, which prevented the TPE melt from fully filling the micro cavity near the pin, caused this imperfection.

The "High" process setting combination resulted in an overall smoother surface on the injection side. This indicates that a better filling of the cavity was achieved thanks to the increased speed and mould temperature. On the other hand, the gate mark was bigger and it significantly protruded from the upper ring surface, representing a serious issue for the suspension ring mounting. The weld line looked also deeper, and a large defect appeared at its end, almost certainly caused by entrapped air. The increased injection speed helped the formation of this imperfection. From the cross-sectional view, it is evident that the internal geometry was more detailed than when utilizing the "Data sheet" process parameters. This enhanced replication was achieved by means of the increased holding pressure. H owever, the rounding on the internal angles was still present. In the ejection side view, similarly to the previous case, an evident defect can be observed on the holecircumference. However, its size was significantly larger due, once again, to the increased injection sped that hel ped the formation of entrapped air near the pin. 
Finally, the rings produced with the "Improved” process settings showed a very small weld line on the injection side. Moreover, the gate mark was smaller than in the "High" case. A comparable level of filling was also achieved as shown by the smooth surface of the suspension ring. No air entrapment seemed to have prevented a complete filling of the part on the injection side. The internal geometry appeared finely detailed. The hole on the ejection side still presented the same type of defect, but its size was consistently reduced if compared to the suspension rings produced with “Data sheet" and "High" process settings.

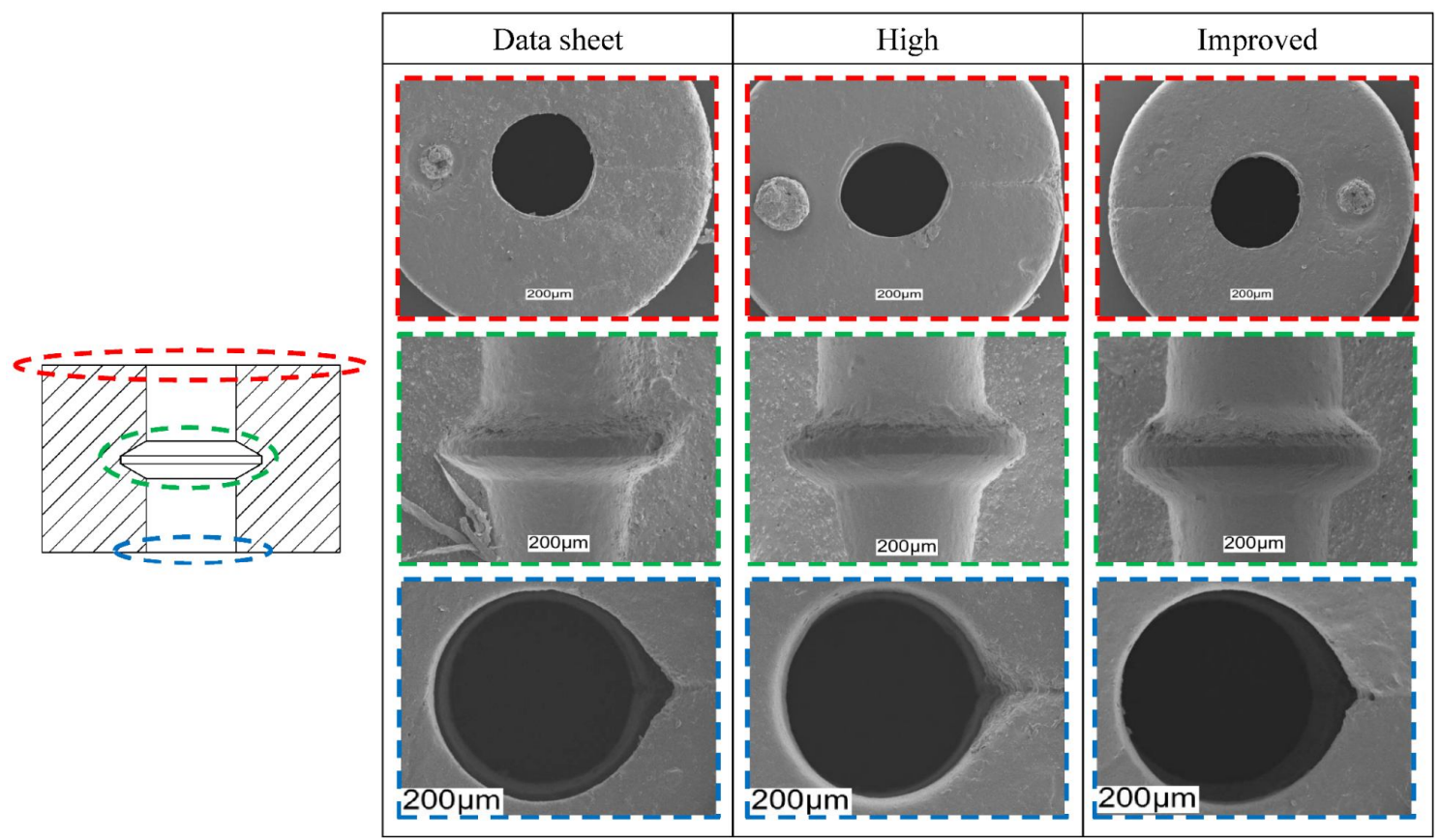

Fig. 6. SEM images of micro rings produced with the three different process settings in the preliminary benchmark study. The injection side view (red), the cross sectional view (green) and the hole on the ejection side (blue) are shown.

In conclusion, the SEM analysis indicated that high pressure and injection speed enhanced the filling of the cavity, but simultaneously generated relevant defects due to air entrapments. Air trap imperfections were mainly observed when moulding with the "Data sheet" and the "High" process settings, indicating that the low values of clamping force and injection speed selected for the "Improved" batch (see Table 3) were decisive in increasing the evacuation of the air from the cavity. This result is in accordance with the study of Griffiths et al. [37], which demonstrated that the volume of evacuated air is lower at higher injection speeds. 
The weld line depth measurements confirmed these findings. In fact, the "Improved" process settings resulted in the smallest weld line depth in all the five measuring positions (see Fig. 7).

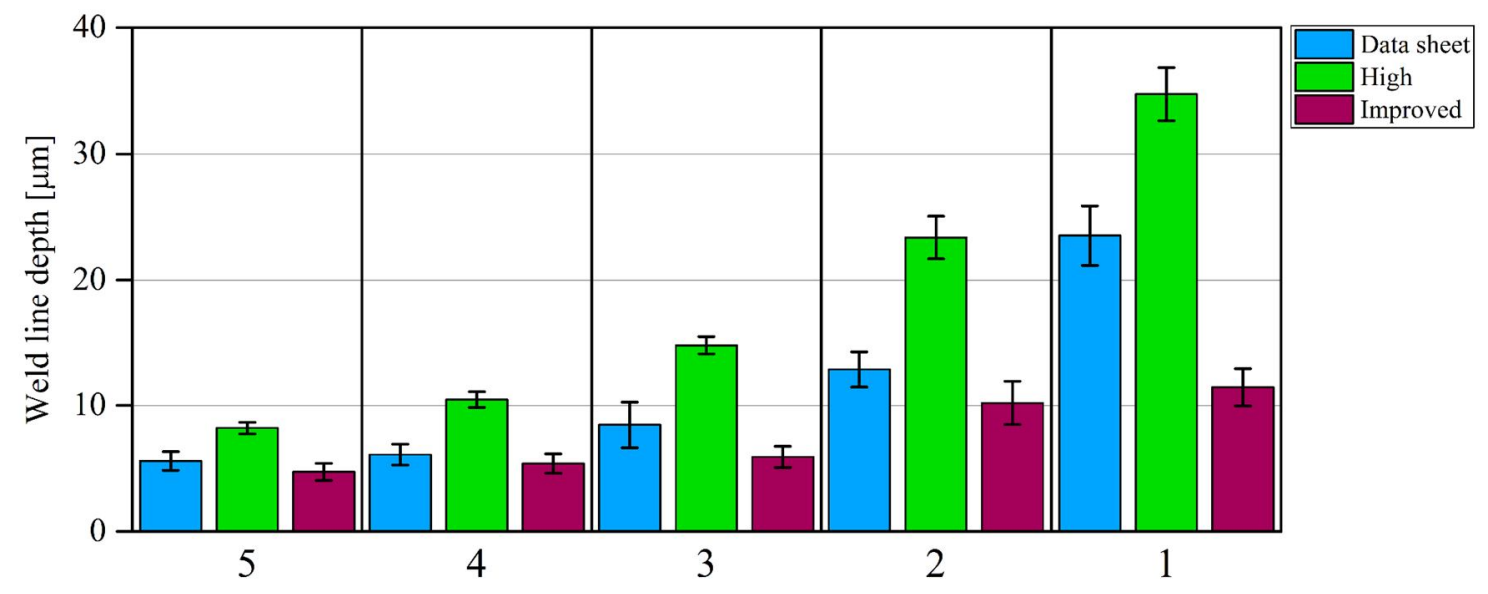

Fig. 7. Weld line depth for the three different setting of the benchmark study in the five different measuring positions. The standard deviations related to the ten different parts are indicated.

On the other hand, the weld line depth was largest for the "High" batch because of the increased injection speed that obstructed the air evacuation from the cavity. Considering the different measuring positions, the weld line was al ways deeper moving from the inner to the outer diameter, proving that the air entrapment was formed on the external part of the cavity, where the polymer flow ended its path.

Eventually, considering both SEM inspections and weld line depth measurements, the "Improved" process settings combination represeneds the best solution since it allowed minimizing the part defects. Therefore, it was chosen as a starting point for defining the levels of the process parameters investigated in the successive DOE investigation. In particular, the clamping force value was always kept at $30 \mathrm{kN}$ in order to allow a proper evacuation of the air from the cavity.

\subsection{M ould cavities measurements results}

The $\mu$ EDM tooling process allowed achieving a very high dimensional accuracy. In fact, the deviations between target and measured dimensions ranged between $-0.4 \mu \mathrm{m}$ and $1.6 \mu \mathrm{m}$ for OD and between $0.8 \mu \mathrm{m}$ and $2.7 \mu \mathrm{m}$ for ID (see Fig. 8). Considering the calculated uncertainties 
(see Table 5), the measured values allowed to meet the mould design specifications except for the inner diameter of cavity 1 and 2.

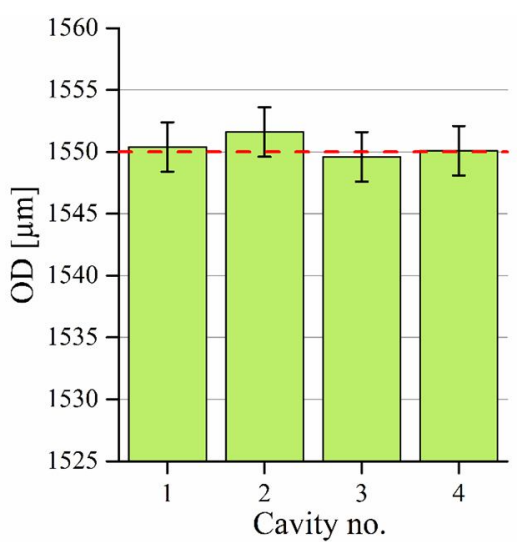

(a)

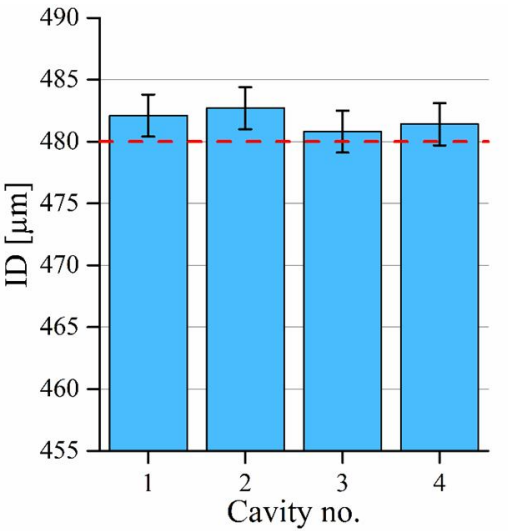

(b)

Fig. 8. Results of cavity measurements for OD (a) and ID (b). The error bars indicate expanded uncertainties, while the red dashed lines represent the mould target dimensions.

\subsection{DOE results}

\subsubsection{OD results}

Fig. 9(a) reports the main effects plot concerning the outer diameter OD measured on the moulded rings. In this plot, along with the usual lines indicating the effects of the experimental factors, the uncertainty related to the particular process parameters combination was added in order to verify that the variability did not hide the influence of the process. 
Fig. 9. Main-effect plots for OD (a) and ID (b). The error bars indicate the expanded uncertainties related to the particular process parameter level. The grey dashed lines show the total averages.

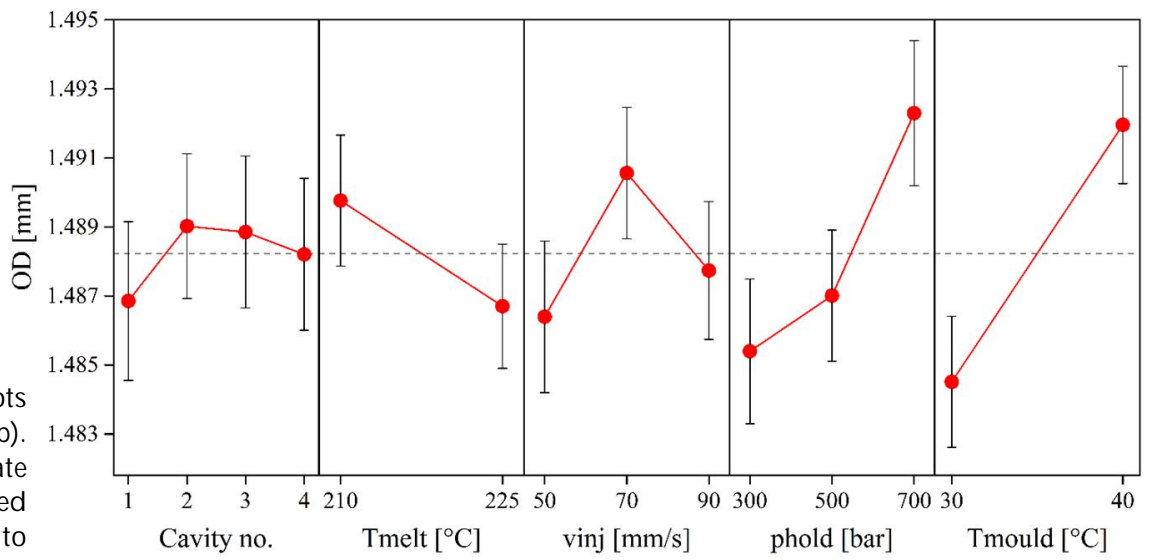

(a)

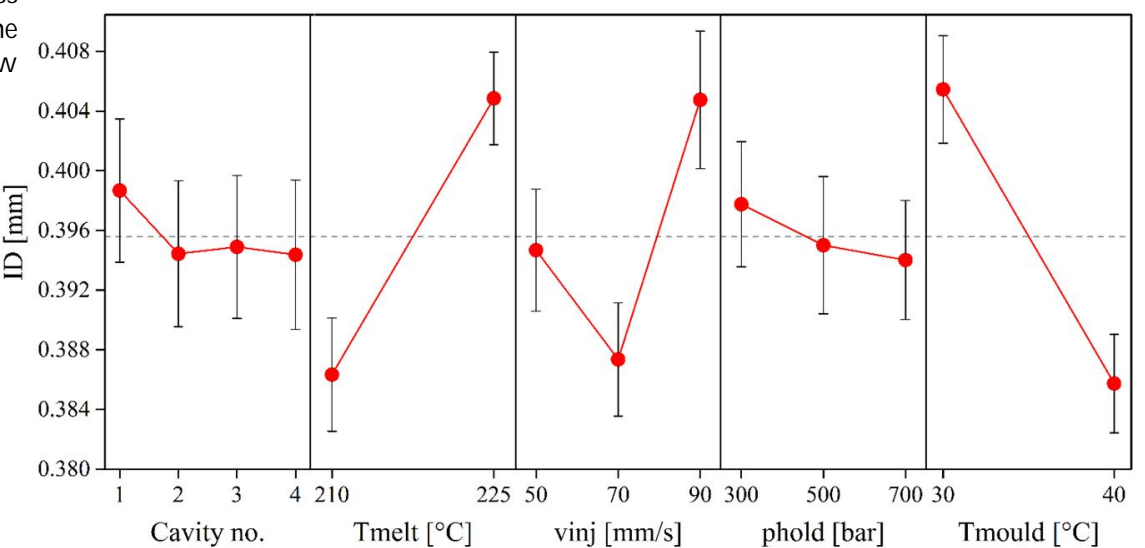

(b)

Firstly, it is possible to observe that the micro TPE rings production was consistent across the four cavities. This is an important result since it proves that, on one hand, the polymer conditions (temperature, shear rate, pressure, and in turn specific volume and final shrinkage) were equivalent in the four cavities. On the other hand, it also proves that, under controlled conditions in terms of micro tooling and moulding processes, it is possible to achieve single digit accuracy and precision in multi-cavity micro moulding. The effects of mould temperature and holding pressure were preponderant since they presented the highest slope indicating a great significance on the response value. The increase of these process parameters had a positive effect on OD. Such a behaviour, which indicates that high mould temperatures and pressures enhanced the filling of the cavity, was also observed in previous $\mu$ IM experiments on rigid thermoplastics [32], [38]. In particular, a high level of T mould opposes a premature cooling and the subsequent raise in viscosity of the polymer melt while a high value of phold allows more material to fill the cavity before the freezing of the gate. The increase of mould temperature and 
holding pressure led to an average increment of $7 \mu \mathrm{m}$ in both the cases. The influence of melt temperature was less relevant. In particular, an increase of $\mathrm{T}_{\text {met }}$ resulted in an average decrease of $3 \mu \mathrm{m}$ of OD. This small negative effect of the melt temperature is unusual, since in most cases a high $\mathrm{T}_{\text {met }}$ helps the filling of the cavity by means of a reduced viscosity. This may have been caused by the fact that, starting from a higher temperature of the melt, the ring outer diameter had undergone a larger amount of shrinkage at the end of the moulding process. Finally, an evident nonlinear relation between OD and the injection speed was observed: by incrementing $v_{\mathrm{inj}}$, the replication level increased due to the faster injection, which decreased the polymer viscosity. However, this behaviour was valid until a certain injection speed, since OD plot presents a negative slope when moving from $70 \mathrm{~mm} / \mathrm{s}$ to $90 \mathrm{~mm} / \mathrm{s}$. This fact, which has al ready been observed by Surace et al.[12] for part mass measurements, indicates that a local optimum for the injection speed existed within the explored range. This phenomenon may be due to an increase of residual stresses that caused a bigger shrinkage of the part OD. Residual stresses are, in fact, typically larger at high injection speeds because of the more drastic cooling rate of the injected polymer melt.

\subsubsection{ID results}

Fig. 9(b) shows the main effects plot for ID measurements. As before, the cavity number did not present any relevance for this output, confirming the high precision of the employed tooling and moulding processes. Onceagain, the mould temperature showed a high significance on the inner diameter value. The increment of $\mathrm{T}$ mould from $30^{\circ} \mathrm{C}$ to $40^{\circ} \mathrm{C}$ resulted in a decrease of ID of $9 \mu \mathrm{m}$. Thus, the mould temperature had an opposite effect on the two measured diameters. Contrary to the previous case, the holding pressure effect was negligible: the uncertainty totally hid the ID values for the three different levels of phold. This difference may be due to the geometry of the part: given the position of the gate (see Fig. 3(b)), the last portion of the cavity filled by the polymer melt stood on the outer ring circumference, as proven by the weld line depth analysis (see Fig. 7). Therefore, the holding pressure, which came to act only in the last phase of the moulding process when the cavity was already almost filled, mainly influenced the 
outer diameter that was filled as last. The influence of the melt temperature was greater than for OD. In particular, the increase of $T_{\text {met }}$ led to an average ID increment of $9 \mu \mathrm{m}$. As for the mould temperature, this trend was opposite with respect to what observed for OD, where the increment of themelt temperature led to a decrease of the measured output. Finally, the injection speed had a non-linear effect on the output. However, as for the other process parameters, this effect was contrary to the one observed when dealing with the outer diameter: the central level of $v_{\text {inj }}$ corresponded to the smallest ID value, whereas it corresponded to the largest OD.

\section{D iscussion}

It was observed that the four process parameters had opposite effects on the two measured diameters. In fact, when OD increased, ID al ways decreased and vice versa. This behaviour was also confirmed by the opposite non-linear effect generated by the injection speed on the two measured outputs. Such a phenomenon has never been observed before for micro-injection moulded components, and it may be directly related to the particular annular geometry of the suspension rings. Being both OD and ID on average smaller than their target dimensions (see Fig. 2), this behaviour poses great challenges in meeting the part's requirements, since a simultaneous increase of both the diameters was impossible to achieve by just tuning the investigated process variables.

With the aim of furtherly investigating the opposite effect of the process parameters on the outer and inner ring diameters, the shrinkage levels of the two measured outputs were compared. In order to carry out this analysis, a reference diameter $D_{\text {ref }}$ was defined (see Fig. 10). This quantity was equal to the average between the OD and ID measured on each one of the four mould cavities and was therefore constant with the cavity number. This particular geometrical reference was chosen since it allows evaluating potential asymmetry of the outer and inner ring diameters. The deviation $\Delta$ was selected as shrinkage indicator. It was calculated as: 


$$
\Delta_{\mathrm{OD}}=\mathrm{OD}-\mathrm{D}_{\text {ref }}
$$

$$
\Delta_{\text {ID }}=\mid \text { ID }-D_{\text {ref }} \text { I }
$$

The absolute value in equation 2 was used in order to quantify the reduction of inner diameter with a positive sign. Fig. 11 reports the main effect plots of $\Delta_{\mathrm{OD}}$ and $\Delta_{\mathrm{ID}}$. The effect of the cavity is not shown since it has al ready been verified that it did not affect the measured outputs. Firstly, it can be observed that the shrinkage of ID was al ways larger than the one involving OD. In particular, the average deviations were equal to $624 \mu \mathrm{m}$ and $469 \mu \mathrm{m}$ for inner and outer diameter respectively. Therefore, the inner diameter shrank more than the outer one, generating a distortion of the initial part design. This phenomenon was most probably caused by the fact that ID was object of constrained shrinkage during moulding, while OD was not. In fact, the presence of the pin did not allow the inner surface to shrink freely during cooling, while the outer one was free to shrink. The constrained shrinkage generated a concentration of tensile stresses in the TPE ring at the inner diameter, causing the higher shrinkage of ID after demoulding. When considering the symmetry of the deformation around the ring axis, it was observed that it was more pronounced for the injection side of the ring because of the nonuniform cooling generated by the asymmetric gate (see Fig. 12).

All the comments related to the process parameters significance are still valid, since $\Delta$ is just scaled by a factor ( $\left.D_{\text {ref }}\right)$ that is almost constant for all the four cavities. As expected, the process parameters had the same influence on the deviations of outer and inner diameters, being the trends of the main effect plot similar in the two cases. However, the magnitude of the process effects, which is evaluable by the slopes of the main effect plot lines, was considerably different. In fact, the process effects resulted much larger for ID. The only exception was represented by the holding pressure influence that was significant only for OD, as explained before. For the other experimental factors, the ratio between the ID and OD slopes ranged from 1.8 (observed between $50 \mathrm{~mm} / \mathrm{s}$ and $70 \mathrm{~mm} / \mathrm{s}$ of injection speed) to 6.0 (observed for the melt temperature), 
proving that the shrinkage behaviour of the inner diameter was significantly more sensitive to the process setting variation.

(a)

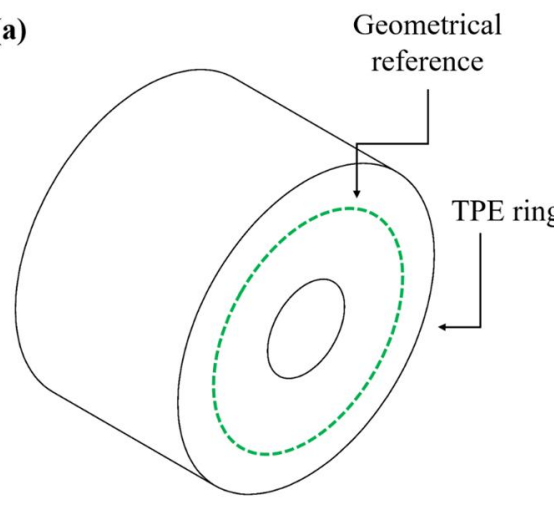

(b)

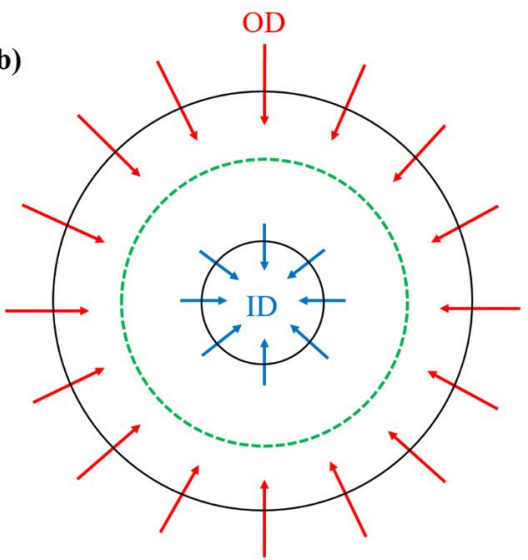

Fig. 10. (a) Side view of the part indicating the position of the geometrical reference. (b) Schematic view for the micro ring shrinkage behaviour.

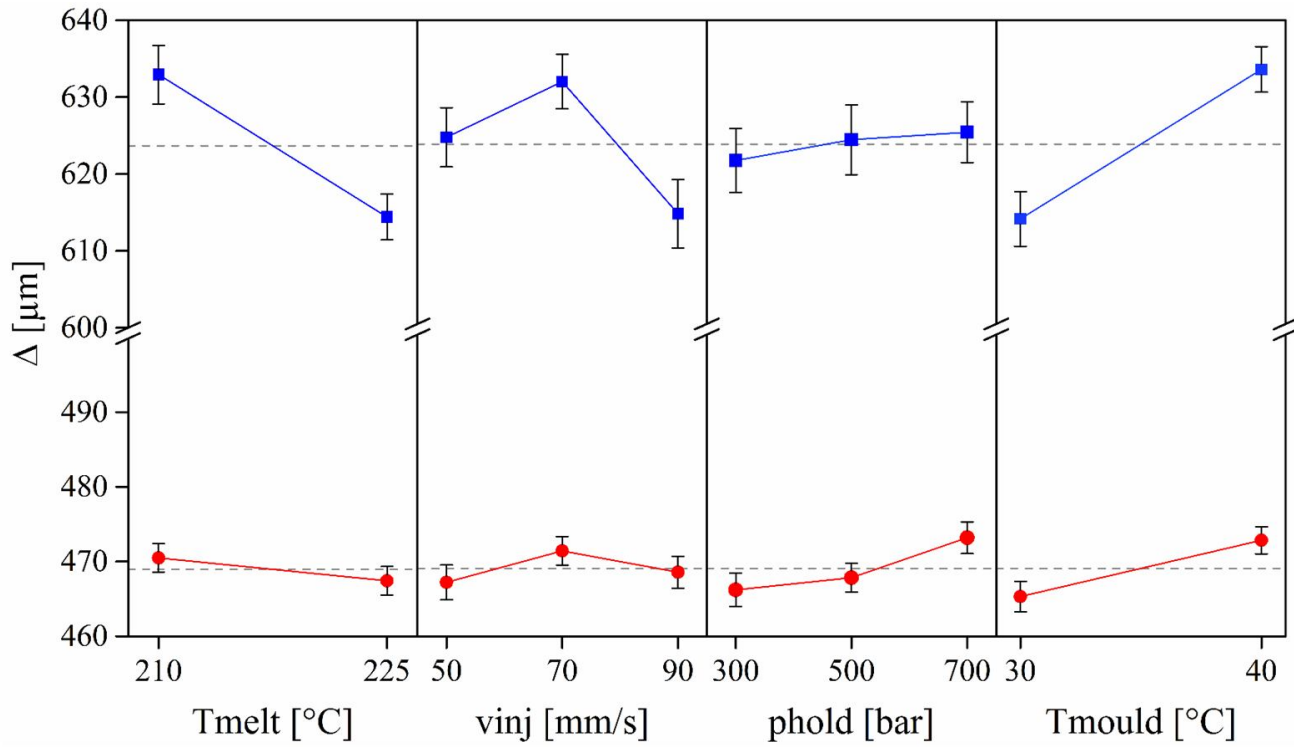

Fig. 11. Combined main effect plots for the deviations $\Delta$ of both OD (in red) and ID (in blue). The error bars indicate the expanded uncertainties related to the particular process parameter level. The grey dashed lines show the total averages. The axes are broken in order to facilitate comparisons among measured trends.

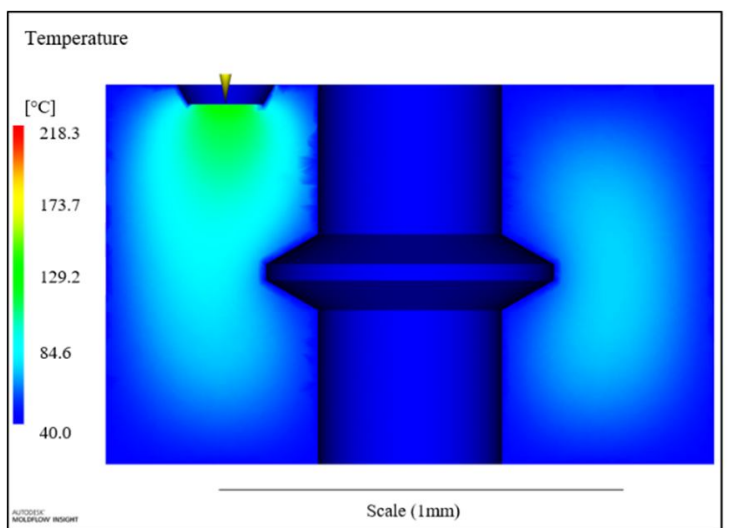

(a)

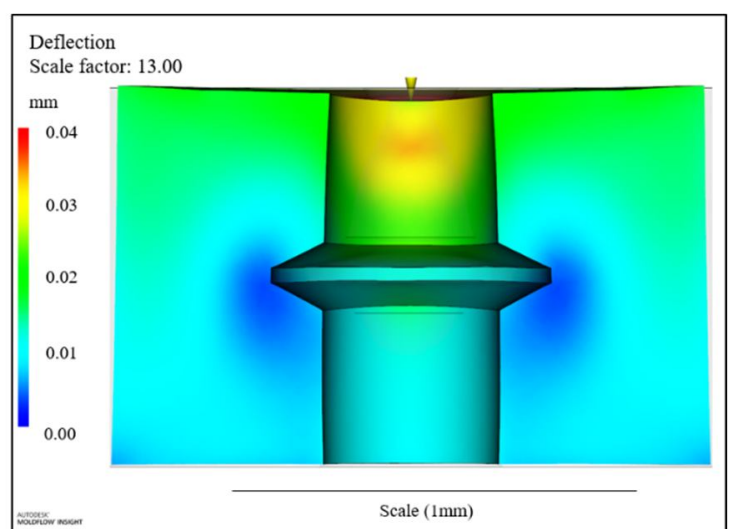

(b)

Fig. 12. (a) Temperature of the TPE material during filling. (b) Process-induced warpage on the micro ring. The yellow cone represents the asymmetric injection location. 


\section{Conclusions}

The present paper studied the $\mu \mathrm{IM}$ technology of micro suspension rings utilized as dampening elements in micro sensor applications. For the first time, a comprehensive investigation has been carried out on a micro component moulded using a thermoplastic elastomer (TPE). The peculiar characteristics of this class of polymeric materials makes them the only candidate for producing micro polymer parts featuring softness and flexibility.

The following conclusions can be drawn from the study:

- As shown in the preliminary benchmark study, low values of clamping force and injection speed were decisive for reducing defects (eg. weld lines) on the part by minimizing air entrapment in the cavity.

- For both outer and inner diameter of the TPE rings, the four different cavities ensured a robust, effectiveand repeatable multi-cavity $\mu \mathrm{IM}$ production, as the measured dimensions in all parts from the four different cavities were equivalent within the single-digit micrometre measurement uncertainty.

- For the outer diameter, mould temperature and holding pressure were the most relevant process parameters. In particular, they both helped in increasing OD. Melt temperature and injection speed were less significant.

- For the inner diameter, mould temperature and melt temperature showed the highest effects. On the other hand, the holding pressure was not significant.

- Both inner and outer diameters showed a non-linear dependence with respect to the injection speed.

- The four process parameters had, in all the experimental cases, an opposite effect on the two measured diameters: an increase of OD always came with a decrease of ID and vice versa. Being the measured diameters smaller than the designed ones, this behaviour poses great challenges in the process optimization.

- Using the average mould diameter as reference, it was found out that the inner diameter shrank more than the outer one. This was caused by the constrained shrinkage that affected the ring inner surface, which was not allowed to shrink freely because of 
the presence of the central pin. Moreover, ID is also more sensitive to the process variations.

Future work will address the study of the $\mu \mathrm{IM}$ process effect on micro rings made of rigid thermoplastic materials. This will allow to determine if the opposite shrinkage behaviour is peculiar of TPEs or not. Moreover, process simulation will also be used to physically investigate the effects of the process parameters on the two measured diameters dimensional variation.

\section{A cknowledgements}

This research work was undertaken in the context of MICROMAN project ("Process Fingerprint for Zero-defect Net-shape MICROMAN ufacturing", http:/ / www.microman.mek.dtu.dk/ ). MICROMAN is a European Training Network supported by Horizon 2020, the EU Framework Programme for Research and Innovation (Project ID: 674801).

\section{References}

[1] Brousseau EB, Dimov SS, Pham DT. Some recent advances in multi-material micro- and nano-manufacturing. Int J A dv Manuf Technol 2010;47:161-80. doi:10.1007/ s00170-009-2214-5.

[2] Alting L, Kimura F, Hansen HN, Bissacco G. Micro Engineering. CIRP Ann 2003;52:635-57.

[3] Giboz J, Copponnex T, MéléP. Microinjection molding of thermoplastic polymers: a review.J Micromechanics Microengineering 2007;17:R96-109. doi:10.1088/ 0960-1317/ 17/ 6/ R02.

[4] Zhiltsova T V., Oliveira MSA, Ferreira JA. Integral approach for production of thermoplastics microparts by injection moulding. J Mater Sci 2012;48:81-94. doi:10.1007/ s10853-012-6669-7.

[5] Whiteside B, Martyn MT, Coates PD, Greenway G, Allen PS, Hornsby P. Micromoulding: process measurements, product morphology and properties. Plast Rubber Compos 2004;33:11-7. doi:10.1179/ 146580104225018346.

[6] Yang C, Yin X-H, Cheng G-M. Microinjection molding of microsystem components: new aspects in improving performance. J Micromechanics Microengineering 2013;23:093001. doi:10.1088/ 0960-1317/ 23/ 9/ 093001.

[7] Yao D, Kim B. Scaling Issues in Miniaturization of Injection M olded Parts. J Manuf Sci Eng 2004;126:733. doi:10.1115/ 1.1813479.

[8] Su Q, Zhang N, Gilchrist MD. The use of variotherm systems for microinjection molding. J A ppl Polym Sci 2016;133:n/ a-n/ a. doi:10.1002/ app.42962.

[9] Hansen HN, Carneiro K, Haitjema H, De Chiffre L. Dimensional micro and nano metrology. CIRP Ann - 
Manuf Technol 2006;55:721-43. doi:10.1016/ j.cirp.2006.10.005.

[10] Attia UM, Marson S, Alcock JR. Micro-injection moulding of polymer microfluidic devices. Microfluid Nanofluidics 2009;7:1-28. doi:10.1007/ s10404-009-0421-x.

[11] Surace R, Bellantone V, Trotta G, BasileV, Modica F, Fassi I. Design and Fabrication of a Polymeric Microfilter for Medical A pplications. J Micro Nano-Manufacturing 2015;4:11006. doi:10.1115/ 1.4032035.

[12] Bellantone V, Surace R, Trotta G, Fassi I. Replication capability of micro injection moulding process for polymeric parts manufacturing. Int J Adv Manuf Technol 2012;67:1407-21. doi:10.1007/ s00170-012-4577-2.

[13] Stormonth-Darling JM, Pedersen RH, How C, Gadegaard N. Injection moulding of ultra high aspect ratio nanostructures using coated polymer tooling. J Micromechanics Microengineering 2014;24:75019. doi:10.1088/ 0960-1317/ 24/ 7/ 075019.

[14] Kayano Y, Zouta K, Takahagi S, Ito H. Replication properties and structure of PC in micromolding with heat insulator mold using zirconia ceramic. Int Polym Process 2011;26:304-12. doi:10.3139/ 217.2440.

[15] Tosello G, Hansen HN, Gasparin S. A pplications of dimensional micro metrology to the product and process quality control in manufacturing of precision polymer micro components. CIRP Ann - Manuf Technol 2009;58:467-72. doi:10.1016/ j.cirp.2009.03.027.

[16] Ontiveros S, Yagüe-Fabra JA, Jiménez R, Tosello G, Gasparin S, Pierobon A, et al. Dimensional measurement of micro-moulded parts by computed tomography. Meas Sci Technol 2012;23:125401. doi:10.1088/ 09570233/ 23/ 12/ 125401.

[17] Lin $\mathrm{HY}$, Chang $\mathrm{CH}$, Young W Bin. Experimental and analytical study on filling of nano structures in micro injection molding. Int Commun Heat Mass Transf 2010;37:1477-86. doi:10.1016/ j.icheatmasstransfer.2010.08.017.

[18] Chen CS, Chen SC, Liao WH, Chien R Der, Lin SH. Micro injection molding of a micro-fluidic platform. Int Commun Heat Mass Transf 2010;37:1290-4. doi:10.1016/ j.icheatmasstransfer.2010.06.032.

[19] Zhang KF, Lu Z. A nalysis of morphology and performance of PP microstructures manufactured by micro injection molding. Microsyst Technol 2008;14:209-14. doi:10.1007/ s00542-007-0412-3.

[20] Marhöfer DM, Tosello G, Islam A, Hansen HN. Gate Design in Injection M olding of Microfluidic Components Using Process Simulations. J Micro Nano-Manufacturing 2016;4:25001. doi:10.1115/ 1.4032302.

[21] Sha B, Dimov S, Griffiths C, Packianather MS. Investigation of micro-injection moulding: Factors affecting the replication quality. J Mater Process Technol 2007;183:284-96. doi:10.1016/ j.jmatprotec.2006.10.019. Griffiths CA, Dimov S, Scholz SG, Hirshy H, Tosello G. Process Factors Influence on Cavity Pressure Behavior in Microinjection Moulding. J Manuf Sci Eng 2011;133:31007. doi:10.1115/ 1.4003953.

[23] Lucchetta G, Sorgato M, Carmignato S, Savio E. Investigating the technological limits of micro-injection molding in replicating high aspect ratio micro-structured surfaces. CIRP Ann - Manuf Technol 2014;63:521-4. doi:10.1016/ j.cirp.2014.03.049.

[24] Masato D, Sorgato M, Lucchetta G. A nalysis of the influence of part thickness on the replication of micro- 
structured surfaces by injection molding. Mater Des 2016;95:219-24. doi:10.1016/ j.matdes.2016.01.115. Lin H-L, Chen C-S, Lee R-T, Chen S-C, Chien R-D, Jeng M-C, et al. Effects of Process Parameters on Replication Accuracy of Microinjection Molded Cyclic Olefins Copolymers Parts. Jpn J A ppl Phys 2013;52:44001. Fu G, Tor SB, Hardt DE, Loh NH. Effects of processing parameters on the micro-channels replication in microfluidic devices fabricated by micro injection molding. Microsyst Technol 2011;17:1791-8. doi:10.1007/ s00542-011-1363-2.

[27] Drobny JG. Handbook of thermoplastic elastomers. William Andrew Pub; 2007.

[28] Varma R, Liu D, Venkataswamy K. TPE Overmolding Technology. A nnu. Tech. Conf. - A ntec, Conf. Proc., vol. 3, 2003, p. 3051-8.

[29] Alabran MW, Mead JL, Barry CMF, Lowell M, Carter DJ, Charles T, et al. Effects of Tooling and Injection Molding Conditions on Nanoscale Replication of Thermoplastic Elastomers. Annu Tech Conf - ANTEC, Conf Proc 2007;85:1990-4.

[30] Attia UM, A Icock JR. A process chain for integrating microfluidic interconnection elements by microovermoulding of thermoplastic elastomers. J Micromechanics Microengineering 2010;20:55017. doi:10.1088/ 0960-1317/ 20/ 5/ 055017.

[31] Mendibil X, Llanos I, Urreta H, Quintana I. In process quality control on micro-injection moulding: the role of sensor location. Int J Adv Manuf Technol 2016. doi:10.1007/ s00170-016-9300-2.

[32] Zhao J, Mayes R, Chen G. Effects of process parameters on the micro molding process. Polym Eng Sci 2003;43.

[33] Wu CH, Liang WJ. Effects of geometry and injection-molding parameters on weld-line strength. Polym Eng Sci 2005;45:1021-30. doi:10.1002/ pen.20369.

[34] Joint Committee for Guides in Metrology (JCGM). Evaluation of measurement data: Guide to the expression of uncertainty in measurement 2008.

[35] Tosello G, Gava A, Hansen HN, Lucchetta G. Study of process parameters effect on the filling phase of microinjection moulding using weld lines as flow markers. Int J Adv Manuf Technol 2010;47:81-97. doi:10.1007/ s00170-009-2100-1.

[36] ISO 15530-3: Geometrical product specifications (GPS) - Coordinate measuring machines (CM M): Technique for determining the uncertainty of measurement 2011.

[37] Griffiths CA, Dimov SS, Scholz S, Tosello G. Cavity Air Flow Behavior During Filling in Microinjection Molding. J Manuf Sci Eng 2011;133:11006. doi:10.1115/ 1.4003339.

[38] Sorgato M, Babenko M, Lucchetta G, Whiteside B. Investigation of the influence of vacuum venting on mould surface temperature in micro injection moulding. Int J A dv Manuf Technol 2016. doi:10.1007/ s00170-016-87898. 